\title{
Investigation of Distribution of Antioxidant Compounds from Natural Sources and Study of Lipid Protection in Oil-in-Water Emulsions
}

\author{
Sylvio V. Palombini, ${ }^{a}$ Fabiana Carbonera, ${ }^{a}$ Marília B. Galuch, ${ }^{a}$ Thiago Claus, ${ }^{a}$

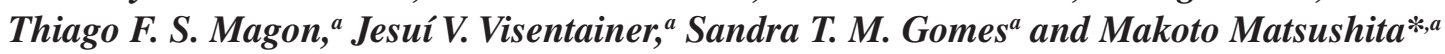 \\ ${ }^{a}$ Departamento de Química, Universidade Estadual de Maringá, \\ Av. Colombo, 5790, 87020-900 Maringá-PR, Brazil
}

\begin{abstract}
The investigation of the distribution of antioxidant compounds between emulsions phases, employing natural sources of these compounds directly in the emulsions, is rarely addressed. The use of ultra performance liquid chromatography coupled to a mass spectrometer (UPLC-MS), combined with accelerated oxidation tests and oxygen radical absorbance capacity method (ORAC), using the fluorescein $(\mathrm{FL})$ decay curve $\left(\mathrm{ORAC}_{\mathrm{FL}}\right)$ assay, enable an improved evaluation of the distribution of the antioxidant compounds and their lipid protection abilities. The lipid protection tendency observed was in agreement with the polar paradox theory. The $\mathrm{ORAC}_{\mathrm{FL}}$ results reported here are higher than other reported in the literature, even when performing a sample extraction directly into one of the emulsion phases, thus demonstrating the effectiveness of this direct addition regarding the antioxidant activity. The analysis of the mass spectra of the emulsions enabled to verify the existence and distribution of some phenolic compounds in both phases. The direct extraction in the aqueous and oil phases of the emulsion increased, in a general way, the amount of identified compounds in each phase.
\end{abstract}

Keywords: polar paradox, rosemary antioxidants, coriander antioxidants, turmeric antioxidants, Oxitest assay

\section{Introduction}

Studies related to antioxidant activity, as well the determination of those compounds responsible for that activity, in various food groups (fruits, grain, legumes, spices and others) are becoming more frequent. ${ }^{1,2}$ Together with these studies, many works are aimed towards the extension of lipid protection of food. ${ }^{3,4}$ Some of these works are based on the study of crude oil protection, whose results offers more elucidations in the relations between antioxidant activity assays (in vitro) and the lipid protection in oils. ${ }^{5,6}$ However, as well as edible oils, many food products based on emulsions (e.g., butter or mayonnaise) are also commercially available. In this way, the study applied to emulsions, whose results can be extrapolated to food products, become very important.

Multiple studies have addressed lipid protection in emulsions. ${ }^{7,8}$ Among these, some try to explain the different trends observed in the polar and nonpolar antioxidants in the different emulsion phases. ${ }^{9}$ The polar paradox theory helps

*e-mail: mmakoto@uem.br to explain many of these results. This theory deals with the greater effectiveness of polar antioxidants in nonpolar media and vice versa.

The findings of some studies support the polar paradox theory., ${ }^{40-12}$ However, the results of other studies are not in accordance with this theory. ${ }^{13-15}$ As such, some authors have attempted to improve the polar paradox theory, ${ }^{16-18}$ employing esters from phenolic acids, such as esters of the acids $p$-hydroxybenzoic, caffeic and vanillic. ${ }^{16,19,20}$ However, some of these compounds (e.g., esters of $p$-hydroxybenzoic acid) are related to serious health problems, such as mammary tumors in humans and reproductive problems in animals, ${ }^{21}$ limiting the future extrapolation of these results to other food sources, as well their application in industrialized foods.

Besides this factor, results from studies employing homologous series of the same phenolic acid, for example, neglect the synergistic and antagonistic effects occurring among the existent antioxidants in a natural food matrix, that might either boost or reduce the level of lipid protection. Thus, the study of the lipid protection in emulsion systems employing a natural source of 
antioxidant, directly to the medium, can be useful, and such findings could be more easily extrapolated to the application of emulsions in industrialized foods. In this way, this work aims to investigate the distribution of antioxidant compounds from natural sources in different phases of emulsions oil/water, as well the lipid protection provided by these compounds. For this, four natural foods were used [rosemary (Rosmarinus officinalis L.), oregano, (Origanum vulgare), coriander (Coriandrum sativum L.) and turmeric (Curcuma longa)], which are all recognized for their high antioxidant activity. ${ }^{22-25}$

\section{Experimental}

Samples

The samples of rosemary (Rosmarinus officinalis L.), oregano (Origanum vulgare), coriander (Coriandrum savitum L.) and turmeric (Curcuma longa) were obtained from a local market in the city of Maringá, Paraná State, Brazil. All the samples were ground and passed through an 80 mesh $(0.177 \mathrm{~mm})$ sieve, to avoid any influence of different particle sizes in subsequent procedures. After sieving, samples were stocked in amber bottles, protected from light, at room temperature.

In emulsions, the oil phase was refined soybean oil, obtained from Cocamar (Cooperativa Agroindustrial de Maringá), without the addition of any antioxidant (natural or synthetic). The aqueous phase was ultrapure water (Milli-Q system, Millipore Corp, Bedford, USA) and the emulsifier was Tween ${ }^{\circledR}$ 80, obtained from Sigma-Aldrich (St. Louis, USA).

\section{Preparation of emulsions}

The emulsions were prepared based on Claus et al. ${ }^{26} \mathrm{In}$ this work it was prepared $12.0 \mathrm{~g}$ of oil-in-water emulsions $\mathrm{O} / \mathrm{W} 50 \%$ (6 $\mathrm{g}$ of oil and $6 \mathrm{~g}$ of water), with a fixed amount of Tween ${ }^{\circledR} 80(0.6 \mathrm{~g})$. The emulsions containing each sample (rosemary, oregano, coriander or turmeric) were prepared in two different ways: the first mode was promoting an extraction of the samples in the oil phase, during $20 \mathrm{~min}$; the second mode was promoting the extraction in the aqueous phase, also for $20 \mathrm{~min}$. In both modes, $120 \mathrm{mg}$ of the samples were added. After the extraction period, the ingredients were mechanically stirred in a test tube using a Vixar Vortex Mixer (Model KMC-1300V), for $3 \mathrm{~min}$ at room temperature. For accelerated oxidation assay $\left(\right.$ Oxitest $\left.^{\circledR}\right)$ blank emulsions were also done, without the addition of sample, containing only oil, water and Tween ${ }^{\circledR} 80$ emulsifier. Table 1 shows all the emulsions done in both modes.
Table 1. Emulsions produced after extractions of the samples in the oil phase or water phase

\begin{tabular}{lc}
\hline Type of extraction & Emulsion \\
\hline Extraction in oil phase & $\begin{array}{c}\text { rosemary in oil/water } \\
\text { oregano in oil/water } \\
\text { coriander in oil/water } \\
\text { turmeric in oil/water }\end{array}$ \\
\hline Extraction in water phase & rosemary in water/oil \\
& oregano in water/oil \\
& coriander in water/oil \\
& turmeric in water/oil \\
\hline
\end{tabular}

Accelerated oxidation assay

The accelerated oxidation tests were performed according to Claus et al. ${ }^{27}$ using the Oxitest ${ }^{\circledR}$ reactor (Velp Scientifica, Usmate, Milan, Italy). The reactor is equipped with two chambers, where the samples are placed, heated to a pre-defined temperature, and oxygen is injected until reaching a defined pressure. The Oxitest measures the pressure drop inside the chamber due to consumption of oxygen by the oxidation reactions that take place in the system. If there is a compound or sample that acts as an antioxidant, the oxidation inside the chamber is delayed. The exact start time of the oxidation processes is obtained by the two-tangent method and is referred to as the induction point (IP). In this study, all tests were conducted at $90^{\circ} \mathrm{C}$ with an initial oxygen pressure of $625 \mathrm{kPa}$, adding $12 \mathrm{~g}$ of a given emulsion to each chamber. The samples (rosemary, oregano, coriander and turmeric) extracted only in oil were also tested, in order to compare the antioxidant behavior of bulk oil against the emulsion system. These oil extractions were done in the same way as the oil phase extractions.

ORAC $_{\mathrm{FL}}$ assays

The oxygen radical absorbance capacity method (ORAC), using the fluorescein (FL) decay curve $\left(\mathrm{ORAC}_{\mathrm{FL}}\right)$ assays were performed in a PerkinElmer fluorescent microplate reader (Victo $^{\circledast}$ X4 Multilabel Plate Reader) using a 9-well black microplate. The emulsions were centrifuged at $5000 \mathrm{rpm}$ for $10 \mathrm{~min}$, to separate the phases. The lipophilic phase was used in the L-ORAC $\mathrm{FL}_{\mathrm{FL}}$, and the hydrophilic phase was used in $\mathrm{H}-\mathrm{ORAC} \mathrm{FL}_{\mathrm{FL}}$ assay.

Previous dilution tests were done to guarantee that analytical signals were within the linear range of the calibration curve constructed using a Trolox (6-hydroxy2,5,7,8-tetramethylchromane-2-carboxilic acid) standard. 
The results of $\mathrm{H}-\mathrm{ORAC} \mathrm{FL}_{\mathrm{FL}}$ and $\mathrm{L}-\mathrm{ORAC} \mathrm{FL}_{\mathrm{FL}}$ were calculated according to Prior et al..$^{28}$ using linear regression $(y=\mathrm{ax}+\mathrm{b})$ between Trolox concentration $\left(\mu \mathrm{mol} \mathrm{L}^{-1}\right)$ and the net area under the fluorescein decay curve. The area under the curve (AUC) was calculated using equation 1 :

AUC $=\left(1+f_{1} / f_{0}+f_{2} / f_{0}+\ldots+f_{n+1} / f_{0}\right)$

where $f_{0}$ is the initial fluorescence intensity and $f_{n}$ is the fluorescence intensity at $\mathrm{n}$ time.

The net AUC value is obtained by subtracting the area under the fluorescence decay curve of the blank from that of a sample or standard. ${ }^{29}$ The results were expressed as $\mu \mathrm{mol} \mathrm{TE} \mathrm{g}^{-1}$ (TE is the Trolox equivalents) of each phase of the emulsion.

For the H-ORAC $\mathrm{FL}_{\mathrm{F}}$ assay, the water phase of each emulsion was diluted with acetone/water/acetic acid $(70: 29.5: 0.5, \mathrm{v} / \mathrm{v} / \mathrm{v})$ to adjust the concentration of the sample to within the range of the standard curve. An aliquot $(20 \mu \mathrm{L})$ of the diluted sample was added to each well of the microplate, followed by $200 \mu \mathrm{L}$ of $95.7 \mathrm{nmol} \mathrm{L}^{-1}$ fluorescein sodium salt solution..$^{28}$ The temperature of the microplate was stabilized at $37^{\circ} \mathrm{C}$. After that, $75.0 \mu \mathrm{L}$ of $8.6 \mathrm{mg} \mathrm{mL}^{-1}$ AAPH (2,2-azobis(2-amidino-propane)dihydrochloride) in $0.075 \mathrm{~mol} \mathrm{~L}^{-1}$ phosphate buffer ( $\mathrm{pH} 7.0$ ) was added to each well. Readings were initiated immediately at $1 \mathrm{~min}$ intervals for $30 \mathrm{~min}$. The wavelengths of excitation and emission were 485 and $515 \mathrm{~nm}$, respectively.

For the L-ORAC $\mathrm{FL}_{\mathrm{FL}}$ assay, $0.050 \mathrm{~g}$ of the oil phase of each emulsion was diluted in $1.5 \mathrm{~mL}$ of acetone and $4.5 \mathrm{~mL}$ of randomly methylated $\beta$-cyclodextrin (RMCD), prepared with 7\% RMCD solution in acetone/water (50:50, v/v). An appropriate concentration was used to be within the linear range of the calibration curve. The 7\% RMCD solution was used as blank and also to dissolve Trolox for the calibration curve. The following procedure for $\mathrm{L}-\mathrm{ORAC}_{\mathrm{FL}}$ was similar to that described for $\mathrm{H}-\mathrm{ORAC} \mathrm{C}_{\mathrm{FL}}$, except that a different concentration of AAPH solution (17.2 $\left.\mathrm{mg} \mathrm{mL}^{-1}\right)$ was added into the system. Both the $\mathrm{H}-\mathrm{ORAC} \mathrm{CL}_{\mathrm{FL}}$ and $\mathrm{L}-\mathrm{ORAC} \mathrm{FL}_{\mathrm{FL}}$ assays were performed in six replicates.

\section{Mass spectra of antioxidant compounds}

The samples were injected in an ultra performance liquid chromatography (UPLC) Aquity H-class system, coupled to a triple quadrupole mass spectrometer Xevo TQD ${ }^{\mathrm{TM}}$ (MS), equipped with an electrospray ionization (ESI-Waters Zspray $^{\mathrm{TM}}$ ) source (Milford, MA, USA). Mobile phase (A) was composed of ultrapure water, while mobile phase (B) was composed of methanol. The mass spectrometry determination was performed with an electrospray source in the negative ion mode. The parameters were as follows: capillary voltage, $3 \mathrm{kV}$; cone voltage, variable according to desirable molecule; desolvation gas temperature, $350{ }^{\circ} \mathrm{C}$; desolvation gas flow, $750 \mathrm{~L} \mathrm{~h}^{-1}$; collision gas, set at a pressure of $3.5 \mathrm{mbar}$; scanning range, 100-700 amu; isocratic flow of a mixture of phase A and B (50:50, v/v) combined with methanol from external pump (flow rate of $0.05 \mathrm{~mL} \mathrm{~min}^{-1}$; sample injection volume, $50 \mu \mathrm{L}$; total run time, $5 \mathrm{~min}$ ). This method consists of a combined flow $(5 \mathrm{~min})$ to perform the injection of the interest sample and injection of a blank (only solvent). After that, to determine the specific spectrum, a subtraction between blank and sample spectrum was done, obtaining the real spectrum of the analytes.

Before the analysis, the emulsions phases were separated by centrifugation at $6000 \mathrm{rpm}$ for $10 \mathrm{~min}$. Each phase (aqueous and oil) was analyzed separately. The aqueous and oil phases of the emulsions were properly diluted in methanol and methanol:chloroform $(50: 50, \mathrm{v} / \mathrm{v})$, respectively, for further use in analysis.

\section{Statistical analysis}

The results were submitted to analysis of variance (ANOVA), and the means were compared by the Tukey's test using the Statistica program, version 7.0. ${ }^{30}$ The significance level used for rejection of the null hypothesis was $5 \%(p<0.05)$.

\section{Results and Discussion}

The Oxitest assay results are shown in Table 2. The IP values show the point where the oil or sample oxidation reaction starts, thus initiating the degradation of the sample. Here, with the aim of facilitating the visualization of the protector effect of samples within oil and emulsions, were calculated the $\Delta \mathrm{IP}$ values by the difference between the IP value of each sample and the IP value of pure oil (in the case of sample + oil mixtures), or the IP value of the blank emulsion (in the case of emulsions). The higher the $\Delta \mathrm{IP}$ value, the greater the protection provided by the sample.

As can be observed in Figure 1, among the tested samples, rosemary had the highest $\Delta \mathrm{IP}$ values, which was more than two-times higher when added to oil than to emulsions. Taking into consideration the polar paradox theory, ${ }^{18,31}$ these results suggest that the rosemary compounds responsible for the antioxidant activity possess a more polar characteristics, due to the higher protection to the bulk oil (nonpolar) than the emulsions (containing polar phase). Oregano did not show difference between the $\Delta \mathrm{IP}$ values of the pure oil and the oil phase in the emulsion. However, showed higher protection when it was added 
Table 2. Induction points and $\Delta \mathrm{IPs}$ for all emulsions and oil + sample mixtures

\begin{tabular}{lcc}
\hline Sample & $\mathrm{IP} / \mathrm{min}$ & $\Delta \mathrm{IP}^{\mathrm{a}} / \mathrm{min}$ \\
\hline Oil & 844 & - \\
Blank emulsion & 957 & - \\
Oil + rosemary & 1598 & 754 \\
Oil + oregano & 928 & 84 \\
Oil + coriander & 861 & 17 \\
Oil + turmeric & 905 & 61 \\
Rosemary in oil/water & 1259 & 302 \\
Rosemary in water/oil & 1280 & 323 \\
Oregano in oil/water & 1041 & 84 \\
Oregano in water/oil & 1072 & 115 \\
Coriander in oil/water & 979 & 22 \\
Coriander in water/oil & 982 & 25 \\
Turmeric in oil/water & 918 & -39 \\
Turmeric in water/oil & 1149 & 192 \\
\hline
\end{tabular}

${ }^{a} \Delta$ IP calculated as the difference between sample IP and crude oil IP (for oil + sample mixture) and between sample IP and blank emulsion IP (for emulsions); IP: induction point.

to the aqueous phase in the emulsion. Coriander was the sample that had the lower values of $\Delta \mathrm{IP}$, indicating to be the sample which less contributed to the protection of both pure oil and emulsions.

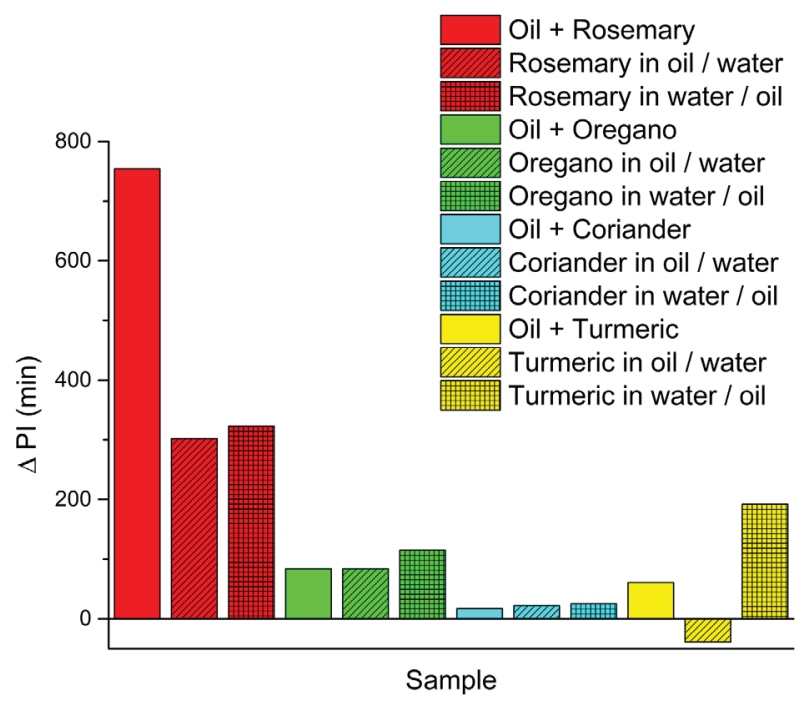

Figure 1. $\Delta \mathrm{IP}$ values $(\mathrm{min})$ for mixtures: sample + oil and sample + emulsion.

Turmeric showed a different result: when added to pure oil, was observed the protection of the oil (positive $\Delta \mathrm{IP}$ value); however, when added to the oil phase of the emulsion, presented a negative $\Delta \mathrm{IP}$ value, suggesting a pro-oxidant action in the emulsion. When turmeric was added to the aqueous phase of the emulsion, showed higher value of $\Delta \mathrm{IP}$, being most effective in the protection of the emulsion than the pure oil. Considering the polar paradox theory, comparing the $\Delta \mathrm{IP}$ values of turmeric added to pure oil against those in the aqueous phase of the emulsion, is expect that the compounds that act as an antioxidant in turmeric have a predominantly non-polar characteristic.

Despite all the differences in the total values of $\Delta \mathrm{IP}$ observed among the samples, it can be noted a general tendency in the results: all the samples, when initially extracted in the aqueous phase of the emulsions, showed higher values of $\Delta \mathrm{IP}$ than for the emulsions prepared after extraction in the oil phase, regardless of the different antioxidant compounds present in the samples. This tendency follows, in parts, the polar paradox principles, since the extraction in the aqueous phase of emulsions will extract, in general, higher levels of polar compounds than nonpolar compounds, with these compounds presenting higher protection to the oil of the emulsions.

The $\mathrm{H}-\mathrm{ORAC} \mathrm{C}_{\mathrm{FL}}$ and $\mathrm{L}-\mathrm{ORAC} \mathrm{FL}_{\mathrm{FL}}$ results are shown in Table 3. In the $\mathrm{H}-\mathrm{ORAC} \mathrm{FL}_{\mathrm{FL}}$ assay, the aqueous phases of emulsions were evaluated. Both emulsions containing oregano (oregano in oil/water and oregano in water/ oil), as well as rosemary in water/oil emulsion showed highest results. The emulsions with coriander and turmeric presented intermediate values, with the emulsions prepared with sample extraction in oil phase showing higher results than those prepared in the aqueous phase.

Table 3. $\mathrm{L}-\mathrm{ORAC} \mathrm{CL}_{\mathrm{FL}}$ and $\mathrm{H}-\mathrm{ORAC} \mathrm{C}_{\mathrm{FL}}$ results for all emulsions tested

\begin{tabular}{lcc}
\hline Emulsion & $\begin{array}{c}\text { H-ORAC } \\
\left(\mu \mathrm{mol} \mathrm{TE} \mathrm{g} \mathrm{g}^{-1}\right)\end{array}$ & $\begin{array}{c}\mathrm{L}-\mathrm{ORAC}_{\mathrm{FL}} / \\
\left(\mu \mathrm{mol} \mathrm{TE} \mathrm{g} \mathrm{g}^{-1}\right)\end{array}$ \\
\hline Rosemary in oil /water & $732.54 \pm 36.78^{\mathrm{d}}$ & $7.15 \pm 0.16^{\mathrm{a}}$ \\
Rosemary in water/oil & $2220.08 \pm 56.29^{\mathrm{a}}$ & $6.83 \pm 0.32^{\mathrm{b}}$ \\
Oregano in oil/water & $2201.82 \pm 270.70^{\mathrm{a}}$ & $3.51 \pm 0.31^{\mathrm{c}}$ \\
Oregano in water/oil & $2204.11 \pm 157.82^{\mathrm{a}}$ & $3.18 \pm 0.08^{\mathrm{c}}$ \\
Coriander in oil/water & $1541.45 \pm 149.79^{\mathrm{b}}$ & $1.45 \pm 0.09^{\mathrm{e}}$ \\
Coriander in water/oil & $1097.93 \pm 172.06^{\mathrm{c}}$ & $1.16 \pm 0.25^{\mathrm{e}}$ \\
Turmeric in oil/water & $1374.97 \pm 52.80^{\mathrm{b}, \mathrm{c}}$ & $3.28 \pm 0.16^{\mathrm{c}}$ \\
Turmeric in water/oil & $675.60 \pm 92.38^{\mathrm{d}}$ & $2.23 \pm 0.03^{\mathrm{d}}$ \\
\hline
\end{tabular}

Results expressed as the mean \pm standard deviation for analysis in three replicates; means followed by different letters in the same column are significantly different by Tukey's test $(p<0.05)$; $\mathrm{H}_{-} \mathrm{ORAC}_{\mathrm{FL}}$ : hydrophilic results of oxygen radical absorbance capacity assay; L-ORAC $\mathrm{FL}_{\mathrm{FL}}$ : lipophilic results of oxygen radical absorbance capacity assay; TE: Trolox equivalents.

In the $\mathrm{L}-\mathrm{ORAC} \mathrm{C}_{\mathrm{FL}}$ assay were evaluated the oil phases of the emulsions. The emulsions with rosemary showed the highest values, followed by emulsions containing oregano, turmeric and coriander. The emulsions presented a general 
tendency as follows: for each sample, the emulsion prepared with extraction in oil phase presented higher values than the emulsion prepared with extraction in the aqueous phase (Figure 2). In relation to total values, the $\mathrm{L}-\mathrm{ORAC}_{\mathrm{FL}}$ assay results were lower than those obtained in the $\mathrm{H}-\mathrm{ORAC} \mathrm{FL}_{\mathrm{FL}}$ assay.

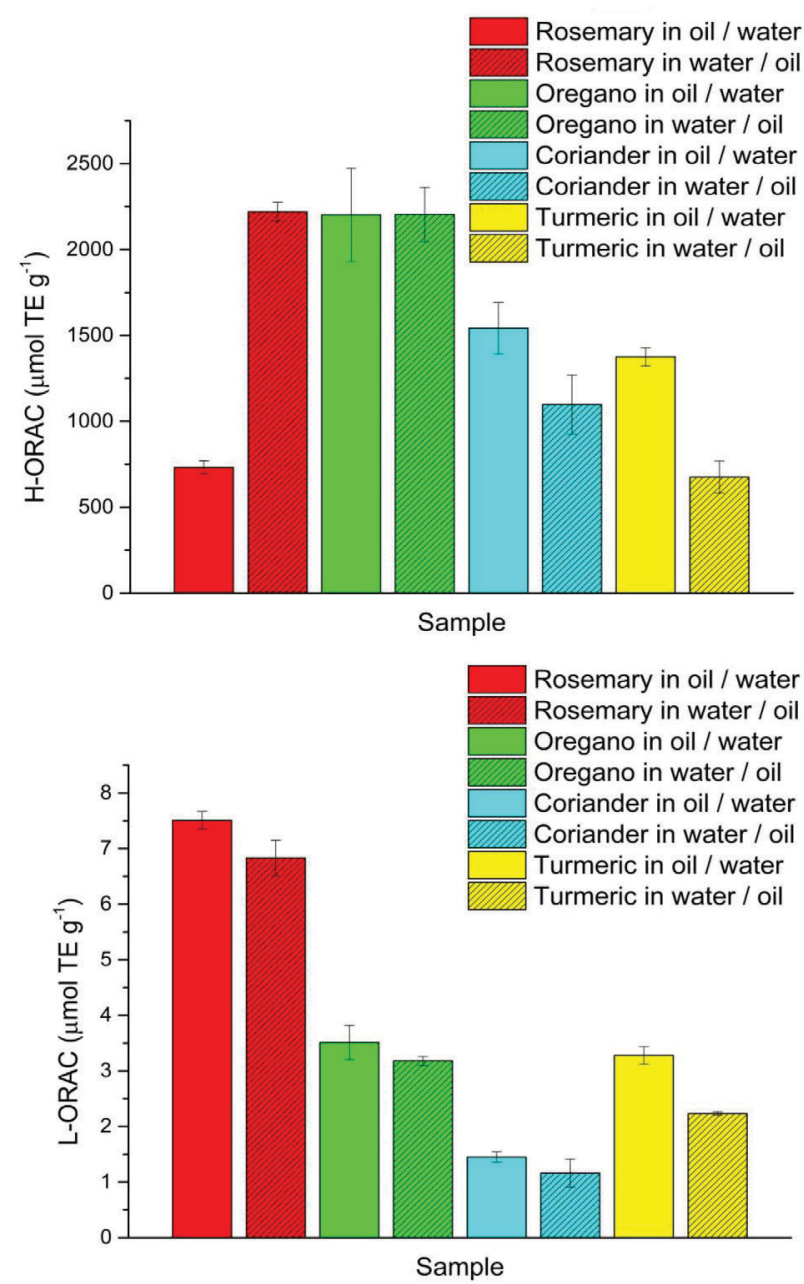

Figure 2. H-ORAC $\mathrm{FL}_{\mathrm{FL}}$ (top) and $\mathrm{L}-\mathrm{ORAC} \mathrm{CL}_{\mathrm{FL}}$ (bottom) results for all emulsions tested.

The H-ORAC $\mathrm{FL}_{\mathrm{FL}}$ results for emulsion rosemary in water/ oil were similar to those reported by Claus et al., ${ }^{26}$ who obtained the medium value of $2065.25 \mu \mathrm{mol} \mathrm{TE} \mathrm{g}{ }^{-1}$. For the $\mathrm{L}-\mathrm{ORAC} \mathrm{FL}_{\mathrm{FL}}$ results, the values obtained for rosemary emulsions were higher than those reported by the same authors $\left(4.03 \mu \mathrm{mol} \mathrm{TE} \mathrm{g}{ }^{-1}\right),{ }^{26}$ which used the same sample amount $(120 \mathrm{mg})$ and equal proportion between emulsion phases (50:50, v/v). However, with higher time of extraction ( $35 \mathrm{~min}$ ) than the employed in this work (20 $\mathrm{min})$.

The oregano emulsions showed higher $\mathrm{H}-\mathrm{ORAC} \mathrm{CL}_{\mathrm{FL}}$ results

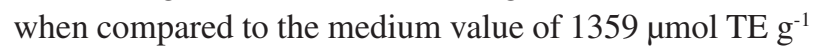
obtained by Claus et al. ${ }^{32}$ employing extraction of the antioxidant compounds in oregano. The results of the oregano emulsions were also close to the $2520 \mu \mathrm{mol} \mathrm{TE} \mathrm{g} \mathrm{g}^{-1}$ reported by Yan et al..$^{33}$ that used ultrasound extraction. The $\mathrm{H}_{-} \mathrm{ORAC} \mathrm{FL}_{\mathrm{FL}}$ results for turmeric emulsions were higher than the $260.81 \mu \mathrm{mol} \mathrm{TE} \mathrm{g}{ }^{-1}$ reported by Kongkachuichai et al. ${ }^{34}$ This indicates that the direct extraction of the antioxidant compounds in one of the emulsion phases provides good results when compared to the other extraction methods.

The MS profiles of the aqueous and oil phases of rosemary emulsions are shown in Figure 3. The MS profiles of the other samples are given in the Supplementary Information section. The interest compounds found in the spectrum were identified by MS/MS fragmentations, as well by comparisons with literature data, containing information about monoisotopic mass and their fragmentations. ${ }^{35-38}$ The unidentified peaks in the shown spectra are not relevant for the purpose of this work.

Aiming a better understanding of the distribution of the compounds through the different emulsion phases, as well as a better elucidation in the antioxidant behavior of the samples in the emulsions, the MS profiles of the aqueous phases were compared, for a given sample, in both modes of emulsion (extraction in water and in oil). The same was realized for oil phases of emulsions (Table 4).

Positive signals indicate higher peak intensity of the observed compound in one type of emulsion, compared to its counterpart. Negative signals indicate lower peak intensity of this same compound relating to its pair. The difference in the peak intensity of a selected compound, under the same ionization conditions, for a given sample, allows the evaluation of a supposed increase or decrease in the quantity of this compound between the emulsion types. In this way, it can be observed that the compounds detected in aqueous phase of rosemary in water/oil emulsion, as well as the detected in aqueous phase of oregano in water/oil emulsion, in a general manner, shows higher peak intensity than the respective phases of rosemary in oil/water and oregano in oil/water emulsions, respectively. This may be an indication of a higher quantity of these compounds in the cited phases, in the emulsions with the extraction of the samples in water, regarding the ones with extraction in oil, indicating that the previous extraction in water may increase the concentration of the compounds in a given phase of the emulsion. This same general trend was observed in the aqueous phase of coriander in water/oil and turmeric in water/oil emulsions.

The detected compounds in the oil phases of rosemary and oregano emulsions showed the opposite tendency: a higher peak intensity in rosemary in oil/water and oregano in oil/water emulsions, indicating that the extraction of oil may increase the concentration of these compounds in the oil phase of these emulsions. On the other hand, the 

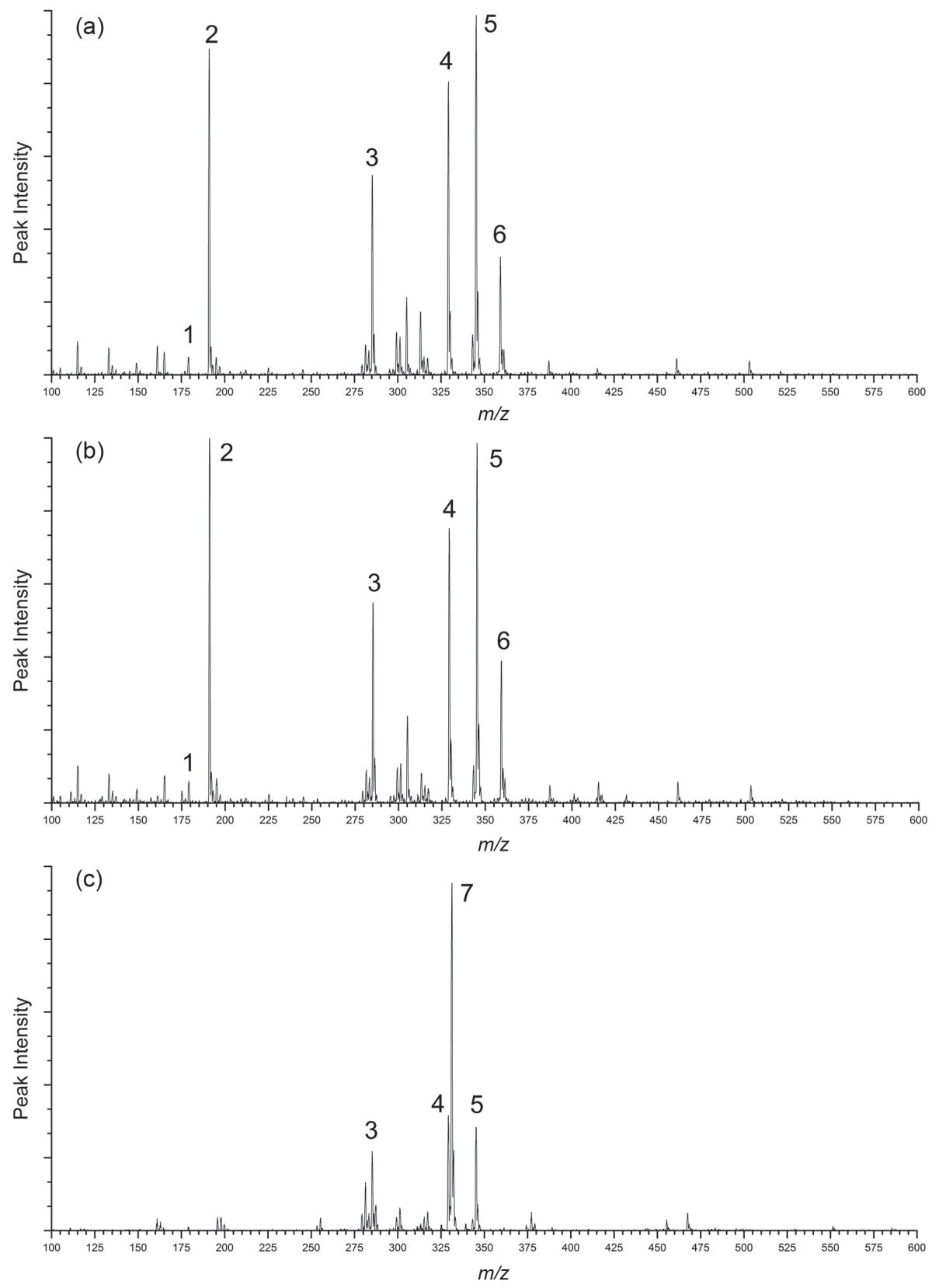

(d)

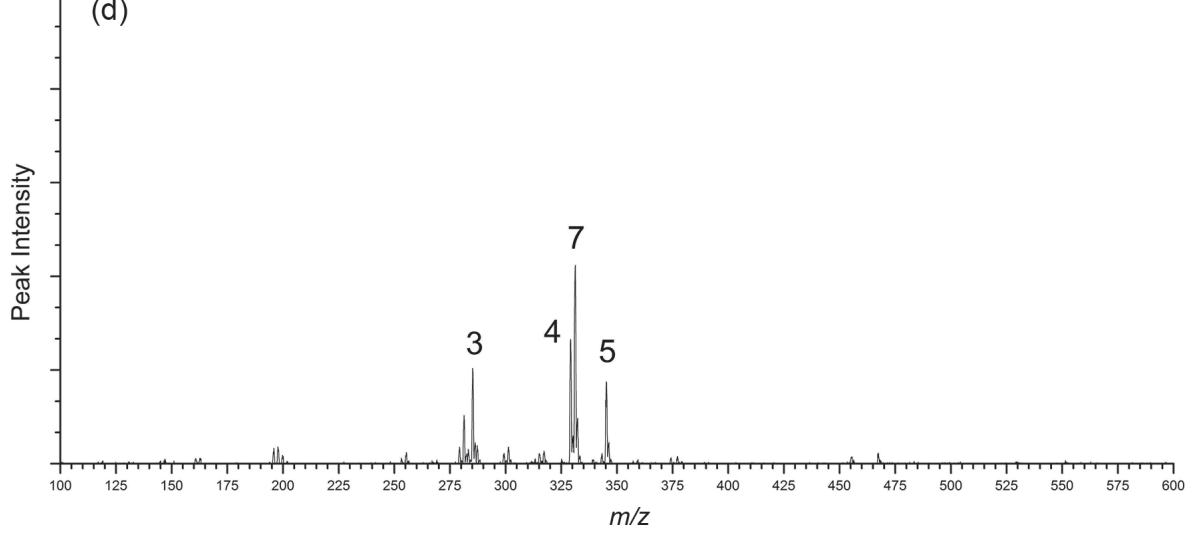

Figure 3. MS spectra for rosemary emulsions. (a) Aqueous phase of rosemary in oil/water emulsion; (b) aqueous phase of rosemary in water/oil emulsion; (c) oil phase of rosemary in oil/water emulsion; (d) oil phase of rosemary in water/oil emulsion. 1: Caffeic acid $(\mathrm{m} / z$ 179.0); 2: quinic acid $(\mathrm{m} / z$ 191.0);

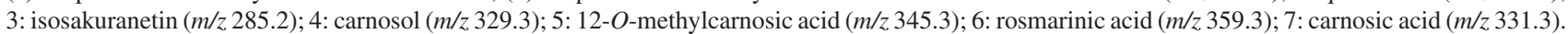


oil phase of the coriander emulsions showed a different tendency, with a higher peak intensity of the identified compound in the coriander in water/oil emulsion. The oil phase of the turmeric emulsions did not show a general tendency, with each compound showing different trends.

Even with the variation of the peak intensity of the phenolic compounds identified, according to the method of preparation of the emulsion, one fact must be highlighted: regardless of the initial extraction of the samples that has been conducted in water or oil, were observed the interest compounds in the aqueous phase of the emulsion. This shows that the time in which the emulsion is prepared (mixture and agitation of the phases) is sufficient to extract a certain quantity of these compounds by the aqueous phase present in the medium. This statement is also valid for oil phases of emulsions.

Another highlight factor is the presence of a same compound in both phases of the emulsion. For rosemary emulsions, this was observed for the following compounds: isosakuranetin, carnosol and 12-O-methylcarnosic acid. For the oregano emulsions, caffeic acid was found in both phases. For the turmeric emulsions, caffeic acid and curcumin were found in both phases. From these results, it seems possible that one of the emulsion phases drags a certain amount of a given antioxidant compound from the other emulsion phase.

Correlating the $\Delta \mathrm{PI}$ obtained values and the MS profiles of the rosemary emulsions, the aqueous phase showed more intense peaks for caffeic, quinic and rosmarinic acids in rosemary in water/oil emulsion, when compared with its pair. This emulsion also returned a higher $\Delta$ PI value than the rosemary in oil/water emulsion. This relationship of a higher amount of these compounds with the higher lipid protection may be an indicator of the direct influence of these compounds on the antioxidant activity of the studied system.

Regarding oregano emulsions, by comparing the MS profiles of the aqueous phase, was detected higher peak intensities for oregano in water/oil emulsion. This emulsion also showed higher $\Delta \mathrm{PI}$ values than oregano in oil/water emulsion. This may be an indication that the identified compounds can act in the lipid protection of the system, in the same way as related before for rosemary emulsions.

On the other hand, most of the compounds detected in the turmeric emulsions presented a different trend of the oregano emulsions: the most intense peaks, in both aqueous and oil phases, were observed in the turmeric in water/oil emulsion. This emulsion also showed higher $\Delta \mathrm{IP}$ values than turmeric in oil/water emulsion. This fact suggests a possible relationship between the detected compounds and the greater lipid protection observed in the accelerated oxidation assay.
Table 4. Comparisons of peak intensity in MS spectra for each phase between emulsions performed with both types of emulsions

\begin{tabular}{|c|c|c|c|}
\hline \multicolumn{4}{|c|}{ Emulsions with rosemary } \\
\hline & & $\begin{array}{c}\text { Rosemary in } \\
\text { oil/water }\end{array}$ & $\begin{array}{c}\text { Rosemary in } \\
\text { water/oil }\end{array}$ \\
\hline \multirow{6}{*}{$\begin{array}{l}\text { Aqueous } \\
\text { phase }\end{array}$} & cafeic acid & - & + \\
\hline & quinic acid & - & + \\
\hline & isosakuranetin & $=$ & $=$ \\
\hline & carnosol & + & - \\
\hline & 12-O-methylcarnosic acid & $=$ & $=$ \\
\hline & rosmarinic acid & - & + \\
\hline \multirow{4}{*}{ Oil phase } & isosakuranetin & + & - \\
\hline & carnosol & + & - \\
\hline & carnosic acid & + & - \\
\hline & 12-O-methylcarnosic acid & + & - \\
\hline \multicolumn{4}{|c|}{ Emulsions with oregano } \\
\hline & & $\begin{array}{l}\text { Oregano in } \\
\text { oil/water }\end{array}$ & $\begin{array}{c}\text { Oregano in } \\
\text { water/oil }\end{array}$ \\
\hline \multirow{3}{*}{$\begin{array}{l}\text { Aqueous } \\
\text { phase }\end{array}$} & protocatechuic acid & + & - \\
\hline & cafeic acid & - & + \\
\hline & quinic acid & - & + \\
\hline \multirow{4}{*}{ Oil phase } & cafeic acid & - & + \\
\hline & carnosol & + & - \\
\hline & carnosic acid & + & - \\
\hline & 12-O-methylcarnosic acid & + & - \\
\hline \multicolumn{4}{|c|}{ Emulsions with coriander } \\
\hline & & $\begin{array}{c}\text { Coriander in } \\
\text { oil/water }\end{array}$ & $\begin{array}{c}\text { Coriander in } \\
\text { water/oil }\end{array}$ \\
\hline \multirow{2}{*}{$\begin{array}{l}\text { Aqueous } \\
\text { phase }\end{array}$} & malic acid & - & + \\
\hline & quinic acid & - & + \\
\hline Oil phase & cafeic acid & - & + \\
\hline \multicolumn{4}{|c|}{ Emulsions with turmeric } \\
\hline & & $\begin{array}{c}\text { Turmeric in } \\
\text { oil/water }\end{array}$ & $\begin{array}{c}\text { Turmeric in } \\
\text { water/oil }\end{array}$ \\
\hline \multirow{5}{*}{$\begin{array}{l}\text { Aqueous } \\
\text { phase }\end{array}$} & malic acid & + & - \\
\hline & cafeic acid & - & + \\
\hline & quinic acid & - & + \\
\hline & curcumin & - & + \\
\hline & demethoxycurcumin & - & + \\
\hline \multirow{2}{*}{ Oil phase } & cafeic acid & + & - \\
\hline & curcumin & - & + \\
\hline
\end{tabular}

Positive signals (+) and negative signals (-) means higher and lower peak intensity, respectively, of a given compound in one type of emulsion (sample in oil/water) when compared with your counterpart (sample in water/oil), in the same phase (aqueous or oil). Equal signals (=) means that do not have a significant difference in the peak intensity of a given compound in the current comparison. 
The coriander emulsions practically do not show difference in $\Delta \mathrm{IP}$ values between emulsions $(22 \mathrm{~min}$ for coriander in oil/water emulsion and $25 \mathrm{~min}$ for coriander in water/oil emulsion), despite the tendency observed for the identified compounds in that emulsions. This indicates that the medium where the extraction was performed (water or oil) does not show a significant interference in the antioxidant activity observed. This might also indicate that these identified compounds can act together with other compounds present in coriander in the lipid protection of the system, not being solely responsible for such protection.

\section{Conclusions}

The results of the accelerated oxidation tests were mostly in line with the polar paradox theory, with most of these results being explained by the theory. The rosemary emulsions had the greatest lipid protection. Regarding the antioxidant activity, evaluated by the $\mathrm{ORAC}_{\mathrm{FL}}$ methodology, the emulsions with oregano and rosemary had high values, higher than those found in literature, which employ previous extraction steps of the antioxidant compounds. It is worth noting that the compound extraction in this work was done directly in one of the emulsion phases, avoiding additional extraction steps and, thus, making the process faster, maintaining the quality of the antioxidant activity results.

The results of the MS profiles for emulsion phases enabled a better monitoring of the distribution of the detected phenolics. It was possible, for example, to observe that the time used to obtain the emulsions is sufficient to extract the compounds of interest by both phases (aqueous and oil). Besides this, were observed the same compounds in both emulsion phases, interesting finding that deserves further works of elucidation of this effect.

The correlation between the tendencies observed in MS profiles and the results of accelerated oxidation tests allowed a better understanding of the relationship between the detected antioxidant compounds and their possible mode of action in the lipid protection. As could be noticed, a given group of phenolic, for example, can exercise different influences in lipid protection of the emulsions, depending on the employed sample. These results path the way for future studies using other natural sources of antioxidants in emulsion systems, as well the possibility of applying these sources to industrialized products, with the aim of improving their antioxidant activity.

\section{Supplementary Information}

Supplementary information (Oxitest ${ }^{\circledR}$ results and mass spectra of emulsions with all samples) is available free of charge at http://jbcs.org.br as PDF file.

\section{Acknowledgments}

The authors would like to thank CAPES, CNPq and Fundação Araucária for financial support and Cocamar (Cooperativa Agroindustrial de Maringá) for the donation of refined soybean oil.

\section{References}

1. Rodriguez-Amaya, D. B.; J. Food Compos. Anal. 2010, 23, 726.

2. Shahidi, F.; Ambigaipalan, P.; J. Funct. Foods 2015, 18, 820.

3. Chen, B. C.; McClements, D. J.; Decker, E. A.; Crit. Rev. Food Sci. Nutr. 2011, 51, 901.

4. Cuvelier, M.-E.; Bondet, V.; Berset, C.; J. Am. Oil Chem. Soc. 2000, 77, 819.

5. Maia, F. J. N.; Ribeiro, F. W. P.; Rangel, J. H. G.; Lomonaco, D.; Luuna, F. M. T.; Lima-Neto, P.; Correia, A. N.; Mazzetto, S. E.; Ind. Crops Prod. 2015, 67, 281.

6. Verardo, V.; Riciputi, Y.; Sorrenti, G.; Ornaghi, P.; Marangoni, B.; Caboni, M. F.; LWT - Food Sci. Technol. 2013, 50, 732.

7. Costa, M.; Losada-Barreiro, S.; Paiva-Martins, F.; Bravo-Diaz, C.; Romsted, L. S.; Food Chem. 2015, 175, 233.

8. Nenadis, N.; Zafiropoulou, I.; Tsimidou, M.; Food Chem. 2003, 82,403 .

9. Frankel, E. N.; Huang, S. W.; Kanner, J.; German, J. B.; J. Agric. Food Chem. 1994, 42, 1054.

10. Huang, S. W.; Frankel, E. N.; Aeschbach, R.; German, J. B.; J. Agric. Food Chem. 1997, 45, 1991.

11. Huang, S. W.; Frankel, E. N.; Schwarz, K.; German, J. B.; J. Agric. Food Chem. 1996, 44, 2496.

12. Huang, S. W.; Hopia, A.; Schwarz, K.; Frankel, E. N.; German, J. B.; J. Agric. Food Chem. 1996, 44, 444.

13. Sasaki, K.; Alamed, J.; Weiss, J.; Villeneuve, P.; López Giraldo, L. J.; Lecomte, J.; Figueroa-Espinoza, M.-C.; Decker, E. A.; Food Chem. 2010, 118, 830.

14. Stockmann, H.; Schwarz, K.; Huynh-Ba, T.; J. Am. Oil Chem. Soc. 2000, 77, 535.

15. Yuji, H.; Weiss, J.; Villeneuve, P.; Giraldo, L. J. L.; FigueroaEspinoza, M. C.; Decker, E. A.; J. Agric. Food Chem. 2007, 55, 11052.

16. Espinosa, R. R.; Inchingolo, R.; Alencar, S. M.; RodriguezEstrada, M. T.; Castro, I. A.; Food Chem. 2015, 182, 95.

17. Laguerre, M.; Bayrasy, C.; Panya, A.; Weiss, J.; McClements, D. J.; Lecomite, J.; Decker, E. A.; Villeneuve, P.; Crit. Rev. Food Sci. Nutr. 2015, 55, 183.

18. Shahidi, F.; Zhong, Y.; J. Agric. Food Chem. 2011, 59, 3499. 
19. Laguerre, M.; Giraldo, L. J. L.; Lecomte, J.; Figueroa-Espinoza, M. C.; Baréa, B.; Weiss, J.; Decker, E. A.; Villeneuve, P.; J. Agric. Food Chem. 2009, 57, 11335.

20. Merkl, R.; Hradkova, I.; Filip, V.; Smidrkal, J.; Czech J. Food Sci. 2010, 28, 275.

21. Soni, M. G.; Carabin, I. G.; Burdock, G. A.; Food Chem. Toxicol. 2005, 43, 985 .

22. Brewer, M. S.; Compr. Rev. Food Sci. Food Saf. 2011, 10, 221.

23. Divya, P.; Puthusseri, B.; Neelwarne, B.; Food Res. Int. 2012, 45, 342.

24. Ribeiro-Santos, R.; Carvalho-Costa, D.; Cavaleiro, C.; Costa, H. S.; Albuquerque, T. G.; Castilho, M. C.; Ramos, F.; Melo, N. R.; Sanches-Silva, A.; Trends Food Sci. Technol. 2015, 45, 355.

25. Zhang, X.-L.; Guo, Y.-S.; Wang, C.-H.; Li, G.-Q.; Xu, J.-J.; Chung, H. Y.; Ye, W.-C.; Li, Y.-L.; Wang, G.-C.; Food Chem. 2014, 152, 300.

26. Claus, T.; Palombini, S. V.; Carbonera, F.; Figueiredo, I. L.; Matsushita, M.; Visentainer, J. V.; J. Braz. Chem. Soc. 2015, 26, 2097.

27. Claus, T.; Maruyama, S. A.; Palombini, S. V.; Montanher, P. F.; Bonafé, E. G.; Santos Jr., O. O.; Matsushita, M.; Visentainer, J. V.; LWT - Food Sci. Technol. 2015, 61, 346.

28. Prior, R. L.; Hoang, H.; Gu, L.; Wu, X.; Bacchiocca, M.; Howard, L.; Hampsch-Woodill, M.; Huang, D.; Ou, B.; Jacob, R.; J. Agric. Food Chem. 2003, 51, 3273.
29. Wu, C.; Duckett, S. K.; Neel, J. P.; Fontenot, J. P.; Clapham, W. M.; Meat Sci. 2008, 80, 662.

30. STATISTICA (Data Analysis Software System), version 7.0; StatSoft Inc.: Palo Alto, USA, 2007.

31. Porter, W. L. In Recent Trends in Food Applications of Antioxidants, $1^{\text {st }}$ ed.; Simic, M. G.; Karel, M., eds.; Plenum Press: New York, 1980, p. 295-365.

32. Claus, T.; Santos Jr., O. O.; Bertozzi, J.; Maruyama, S. A.; Palombini, S. V.; Pilau, E. J.; Camara, C. A. P.; Matsushita, M.; Visentainer, J. V.; J. Braz. Chem. Soc. 2015, 26, 466.

33. Yan, F.; Azizi, A.; Janke, S.; Schwarz, M.; Zeller, S.; Honermeier, B.; Ind. Crops Prod. 2016, 92, 19.

34. Kongkachuichai, R.; Charoensiri, R.; Yakoh, K.; Kringkasemsee, A.; Insung, P.; Food Chem. 2015, 173, 838.

35. Barros, L.; Dueñas, M.; Dias, M. I.; Sousa, M. J.; Santos-Buelga, C.; Ferreira, I. C. F. R.; Food Chem. 2012, 132, 841.

36. Kontogianni, V. G.; Tomic, G.; Nikolic, I.; Nerantzaki, A. A.; Sayyad, N.; Stosic-Grujicic, S.; Stojanovic, I.; Gerothanassis, I. P.; Tzakos, A. G.; Food Chem. 2013, 136, 120.

37. Park, J. B.; Int. J. Food Sci. Nutr. 2011, 62, 577.

38. Vallverdu-Queralt, A.; Regueiro, J.; Martinez-Huelamo, M.; Alvarenga, J. F. R.; Leal, L. N.; Lamuela-Raventos, R. M.; Food Chem. 2014, 154, 299.

Submitted: July 27, 2017 Published online: February 26, 2018 